\section{Critical flicker frequency in the bushbaby, Galago senegalensis}

\author{
JEANNETTE P. WARD and R. STEPHEN DOERFLEIN \\ Memphis State University, Memphis, Tenn. 38111
}

The capacity of the bushbaby, Galago senegalensis, to discriminate intermittent visual stimuli was investigated. Critical flicker frequency (CFF) was estimated at four flash intensities by a modified method of limits. The maximum behavioral CFF obtained for this nocturnal prosimian was $27.4 / \mathrm{sec}$. Results were discussed in terms of the retinal structure of galago and were compared to human scotopic CFF.

In the study of vision, prosimian primates have, until recently, been neglected as compared to their anthropoid counterparts. Among the primitive primates, the galagos, as nocturnal primates, constitute a group of particular interest. The vision of one species, Galago crassicaudatus, has received comparative study by Ordy \& Samorajski (1968) and intensive study by Dartnall, Arden, Ikeda, Luck, Rosenberg, Pedler, \& Tansley (1965), with coordinated behavioral testing by Silver (1966). The visual capacities of a highly similar, but smaller, member of the same genus, Galago senegalensis, have not been explored, although this species is exceptionally suitable for behavioral testing.

In the conduct of previous studies with $G$. senegalensis which required the discrimination of intermittent visual stimuli (Ward, Doerflein, \& Riley, 1970; Ward, Yehle, \& Doerflein, 1970 ), it was necessary to determine the highest rate of intermittent visual stimulation which could be discriminated by this species. This is a report of some critical flicker frequency (CFF) values determined for $G$. senegalensis with high-intensity stimuli.

\section{EXPERIMENT 1}

The purpose of the first experiment was to determine the approximate range of frequencies within which the CFF of the bushbaby falls.

Subjects

Two adult male experimentally naive bushbabies were tested in this experiment. Both Ss were maintained a minimum of 1 month in the laboratory prior to training, were housed individually in $18 \times 24 \times 30$ in. cages, and were fed an ad lib diet of fresh fruit, horsemeat, and cat chow. Apparatus

The testing apparatus was a two-way shock avoidance box, $2 \times 1 \times 2 \mathrm{ft}$, constructed of Plexiglas and with a grid floor. The top and three sides were flat black. A fourth side of clear Plexiglas permitted viewing of the animal during testing through a one-way window. A 0.5 -sec scrambled shock of $0.8-1.0 \mathrm{~mA}$ was delivered to the $1 / 4$-in.-diam bars of the grid floor. Masking noise was furnished by a Grason-Stadler white-noise generator through a University Sound M-12T speaker. Noise level inside the apparatus was $70 \mathrm{~dB}$, as measured by a General Radio Type 1555-A Sound Survey Meter.

The stimulus presentation area was a 3-in.-diam circular aperture in the center of one long side; the position of the stimulus served to separate the two halves of the rectangular apparatus. The bottom edge of the aperture was 3 in. above the level of the grid floor. A diffusing surface, composed of a sheet of fine tracing paper between two $4 \times 4$ in. squares of $1 / 16$-in. clear Plexiglas, was fixed over the aperture. During intertrial intervals the stimulus light was blocked from this aperture by a solenoid-operated light shield.

The stimulus source was a General Electric strip filament lamp. Illumination from this lamp was collimated by a lens and interrupted intermittent visual stimuli. by a sectored disk driven by a variable-speed motor. Disk rpm was calibrated by means of a stroboscope. Luminosity of the high flicker rate was $102 \mathrm{fL}$ at the diffusing surface, as measured by a brightness spot meter. The average ambient illumination of the apparatus was $.4 \mathrm{fL}$.

Procedure

Before training was initiated, two sessions of habituation to the apparatus and one session of stimulus habituation were given. The Ss were trained in the evening during their normally active period. Since the Ss were in darkness in the home cage, they were allowed $15 \mathrm{~min}$ to adapt to the ambient illumination of the apparatus immediately prior to each session.

The Ss were trained on a go/no-go discrimination response. The no-go stimulus was always of 10-sec duration. If the $S$ remained on the same side, the stimulus was terminated at the end of the period. If, however, $S$ crossed to the opposite side during this stimulus period, a shock was delivered, $S$ returned to the correct side, and the no-go stimulus continued for the remainder of the period. Following the onset of the go stimulus, Ss were allowed $10 \mathrm{sec}$ to cross to the opposite side. The stimulus was terminated immediately upon a correct response. If $S$ had not crossed at the end of the go stimulus period, a shock was delivered, and the stimulus terminated simultaneously with the crossing leap.

The interval between trials was $50 \mathrm{sec}$, and random crosses during this interval were not followed by shock.

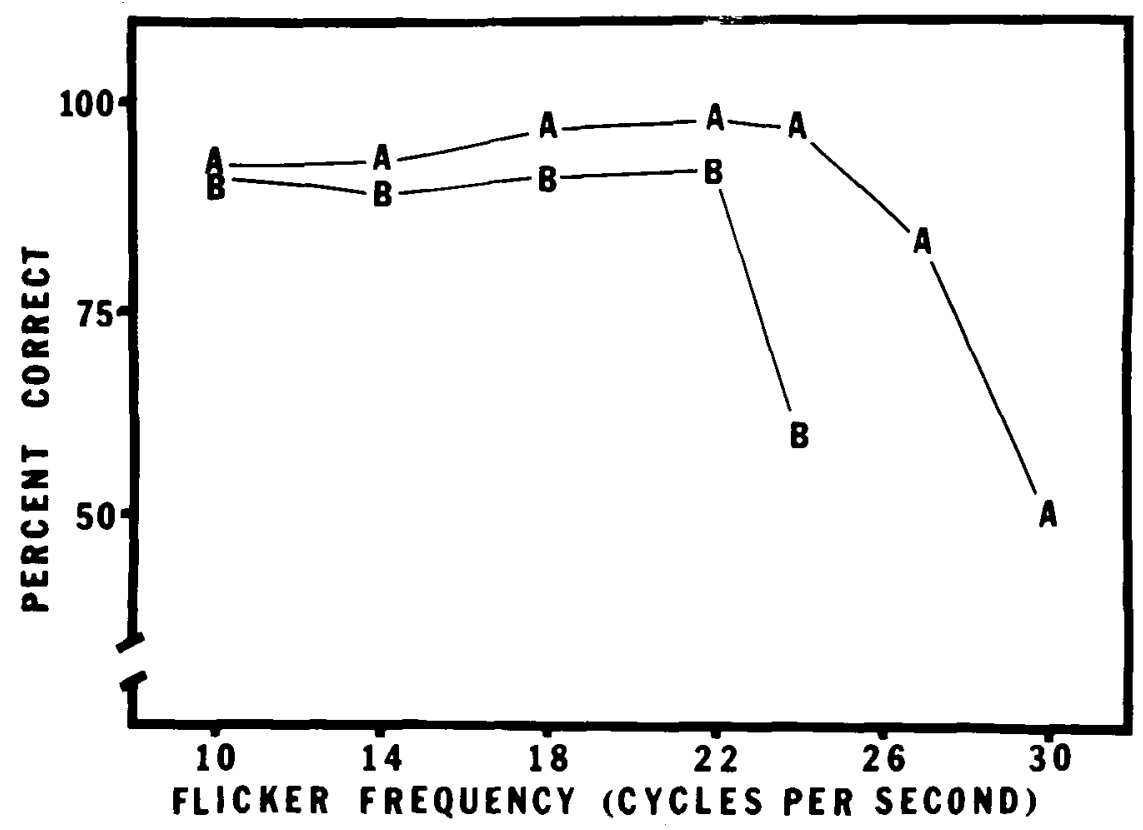

Fig. 1. Performance of two bushbabies, $A$ and $B$, in the discrimination of 
One session of 20 trials was given each day. The 20 trials of each session were equally divided between go and no-go conditions, and the order of stimulus presentation was determined randomly, with the constraint that no more than three consecutive presentations of the same stimulus were allowed.

Both Ss were initially trained to make an active avoidance response when the stimulus light was interrupted at the rate of $10 / \mathrm{sec}$ and a passive avoidance response to a stimulus of $100 / \mathrm{sec}$. The stimulus area was dark during the intertrial intervals. When the performance of this discrimination had stabilized, as indicated by three consecutive sessions at $90 \%$ correct or better, the frequency of the stimulus for active avoidance was increased to the lowest test value $(14 / \mathrm{sec})$ and the $S s$ retrained. The criterion for termination of training on any one test value was five consecutive sessions with no improvement in discrimination performance. Testing was discontinued when performance of the discrimination was at chance. Frequencies tested were $14,18,22$, 24,27 , and 30 flashes/sec.

$$
\text { Results }
$$

The results of this preliminary test are shown in Fig. 1. The discrimination of the $100 / \mathrm{sec}$ (or steady light stimulus) from the lower rate stimuli was maintained well up to and including $22 / \mathrm{sec}$ for both $\mathrm{Ss}$. Beyond this point, the performance of one of the $\mathrm{Ss}$ deteriorated in the discrimination of $24 / \mathrm{sec}$, and that of the second $S$ dropped to chance in the discrimination of $30 / \mathrm{sec}$. From these results it was concluded that the maximum CFF for the bushbaby was probably within the range of 24 to $30 / \mathrm{sec}$.

\section{EXPERIMENT 2}

The purpose of the second experiment was to estimate the upper limits of the bushbaby's ability to discriminate intermittent visual stimuli. The apparatus and procedure of the second experiment were identical with those of the first with two exceptions. These alterations in stimuli and procedure are discussed below.

\section{Subjects}

Two adult male bushbabies were tested. Both of these had previously been trained in the discrimination of intermittent stimuli over an extended period. One of the Ss had been tested in Experiment 1 (A, Fig. 1). The second had undergone prolonged training in the discrimination of both visual and auditory intermittent stimuli in a study reported elsewhere (Ward, Yehle, \& Doerflein, 1970). To use Ss well trained in the discrimination of intermittent stimuli seemed advisable, since a previous study had recorded a dramatic improvement in discrimination performance, and consequently in obtained CFF, as a function of extended training (Mishkin \& Weiskrantz, 1959).

\section{Apparatus}

The same apparatus was used as in Experiment 1. A major change was effected, however, in the stimulus source. A Grass PST-2 flash lamp driven by a Grass PS-2 photostimulator served as the stimulus source. The flash lamp, encased in a wooden housing, was mounted 2 in. behind the diffusing surface of the stimulus presentation area. Frequency and intensity of the stimulus flash were controlled by the photostimulator. The four intensity levels used were measured by means of a brightness spot meter at the diffusing surface as $43,92,225$, and $430 \mathrm{fL}$ at a flash rate of $40 / \mathrm{sec}$.

The change in stimulus source was necessary to make possible the presentation of high intensity stimuli and to render the results of testing more directly comparable with measured ERG-CFF in the bushbaby (Ordy \& Samorajski, 1968). All other conditions associated with the apparatus were as described above. Procedure

The details of behavioral training and testing procedures were similar to those of Experiment 1. The main departures from the previous procedures were (1) a counterbalancing of stimulus contingencies and (2) a modification of the method of limits in the presentation of test stimuli.

One S (A) was required to make a passive avoidance to the flickering and an active avoidance to the steady light; the second $S$ (C) had the converse stimulus contingencies. Both $\mathrm{Ss}$ were initially trained in a basic discrimination of $18 / \mathrm{sec}$ vs $40 / \mathrm{sec}$. Because of some limitations of this flash lamp at high intensities and in accordance with the results of Experiment 1, 40/sec was selected as the above-fusion or steady light stimulus.
Both Ss were trained and tested on four levels of stimulus intensity. The Ss were first trained and tested on the lowest flash intensity (43 fL) and subsequently retrained and retested on each higher flash intensity $(92,225$, and $430 \mathrm{fL}$ ) in an ascending order. The training and testing was discontinued when an increase in flash intensity no longer resulted in an increase in the obtained CFF.

After performance in the basic discrimination at each stimulus intensity was stabilized at a high level, the testing procedure was initiated. As in Experiment 1, an ascending method of limits was used, but, in this instance, in conjunction with the equivalence method. In each session 20 trials were given. Of these, 16 trials were of the basic discrimination, $18 / \mathrm{sec}$ or $40 / \mathrm{sec}$ in equal numbers. A test stimulus was given once in every five trials. The presentation of these test stimuli composed the equivalence trials. On these trials the response of the $\mathbf{S}$ was recorded, either active or passive avoidance, but no shock was contingent upon the response. This method of testing had the advantage of maintaining a high level of discrimination performance even as threshold was approached. If more than two errors were made in the basic discrimination in any session, that session was discarded and rerun. Therefore, the test trials were all taken from sessions in which performance in the basic discrimination was at $87 \%$ correct or better. Each test stimulus was presented 20 times over a total of five sessions before proceeding to the next higher test stimulus value. The frequency values tested at each of four flash intensities are shown in Table 1. Results

The percent flicker response for each of the two Ss, as a function of frequency and intensity of the test stimuli and the estimated CFF, are shown in Table 1. Despite the fact that the flicker response for one $S$ was active avoidance while that for the second was passive avoidance, the scores are in substantial agreement. It is of in terest, however, that the highest estimates of CFF for the two Ss occurs at different flash intensities. It is not
Table 1

Percent Test Stimuli Judged as Flickering and Derived CFF

\begin{tabular}{|c|c|c|c|c|c|c|c|}
\hline \multirow[b]{2}{*}{$\mathbf{s}$} & \multirow{2}{*}{$\begin{array}{l}\text { Stimulus } \\
\text { Intensity } \\
\text { (fL) }\end{array}$} & \multicolumn{5}{|c|}{ Frequency (Cycles/Sec) } & \multirow[b]{2}{*}{ CFF } \\
\hline & & 20 & 22 & 24 & 26 & 28 & \\
\hline A & $\begin{array}{r}43 \\
92 \\
225 \\
430\end{array}$ & $\begin{array}{r}90 \\
95 \\
100 \\
95\end{array}$ & $\begin{array}{l}75 \\
90 \\
95 \\
95\end{array}$ & $\begin{array}{r}50 \\
65 \\
90 \\
100\end{array}$ & $\begin{array}{l}\overline{10} \\
90 \\
65\end{array}$ & $\begin{array}{l}- \\
- \\
10 \\
20\end{array}$ & $\begin{array}{l}24 \\
24.5 \\
27 \\
26.6\end{array}$ \\
\hline C & $\begin{array}{r}43 \\
92 \\
225 \\
430\end{array}$ & $\begin{array}{r}95 \\
100 \\
- \\
-\end{array}$ & $\begin{array}{c}75 \\
100 \\
- \\
-\end{array}$ & $\begin{array}{r}50 \\
95 \\
90 \\
100\end{array}$ & $\begin{array}{l}- \\
85 \\
75 \\
70\end{array}$ & $\begin{array}{l}- \\
35 \\
10 \\
15\end{array}$ & $\begin{array}{l}24 \\
27.4 \\
26.8 \\
26.7\end{array}$ \\
\hline
\end{tabular}


possible to tell if this minor difference represents a variation in sense capacity or a difference in discrimination performance. The latter is unlikely, since performance in the basic discrimination was asymtotic for both animals, and both made the discrimination from the same position, approximately $1 \mathrm{ft}$ from the stimulus surface.

The average performance of these two Ss on points tested is represented in Fig. 2. It should be noted that as flicker frequency was increased, the percent flicker response fell well below $50 \%$, indicating that the $\mathrm{S}$ was giving the steady light response predominantly. In no case, regardless of flash intensity, did either $\mathrm{S}$ judge $28 /$ sec as flickering on as many as $50 \%$ of the trials. Therefore, it appears that $28 /$ sec may be above the upper limit of this species' capacity to resolve intermittent visual stimuli. Certainly, the highest estimated CFF was $27.4 / \mathrm{sec}$ for one $\mathrm{S}$ and $27 / \mathrm{sec}$ for the second.

Discussion

The behavioral estimates of CFF obtained compare favorably with the photopic ERG-CFF of $25 / \mathrm{sec}$ and $30 / \mathrm{sec}$ recorded for two members of the closely related species G. crassicaudatus (Ordy \& Samorajski, 1968). These values are, however, somewhat higher than the maximum CFF of 20/sec reported for the human rod-monocromat (Hecht, Shlaer, Smith, Haig, \& Peskin, 1948).

It has been proposed that CFF may be related either to type of receptor (Hecht \& Verrijp, 1933a, b; Svaetichin, 1956) or size of receptive field (Dodt \& Wirth, 1953; Harvey, 1970). Both of these variables are related to the structural characteristics of the retina. The retina of three species of galago has been described (Dartnall et al, 1965; Detwiler, 1939; Kolmer, 1930; Ordey \& Samorajski, 1968 ) as of nocturnal type with rod receptors and with a high receptor to ganglion cell ratio. Since there is as yet no evidence of more than one type of receptor, it is tentatively suggested that the higher maximum CFF of the bushbaby, as compared to the human scotopic function, may reflect a difference in receptive field size.

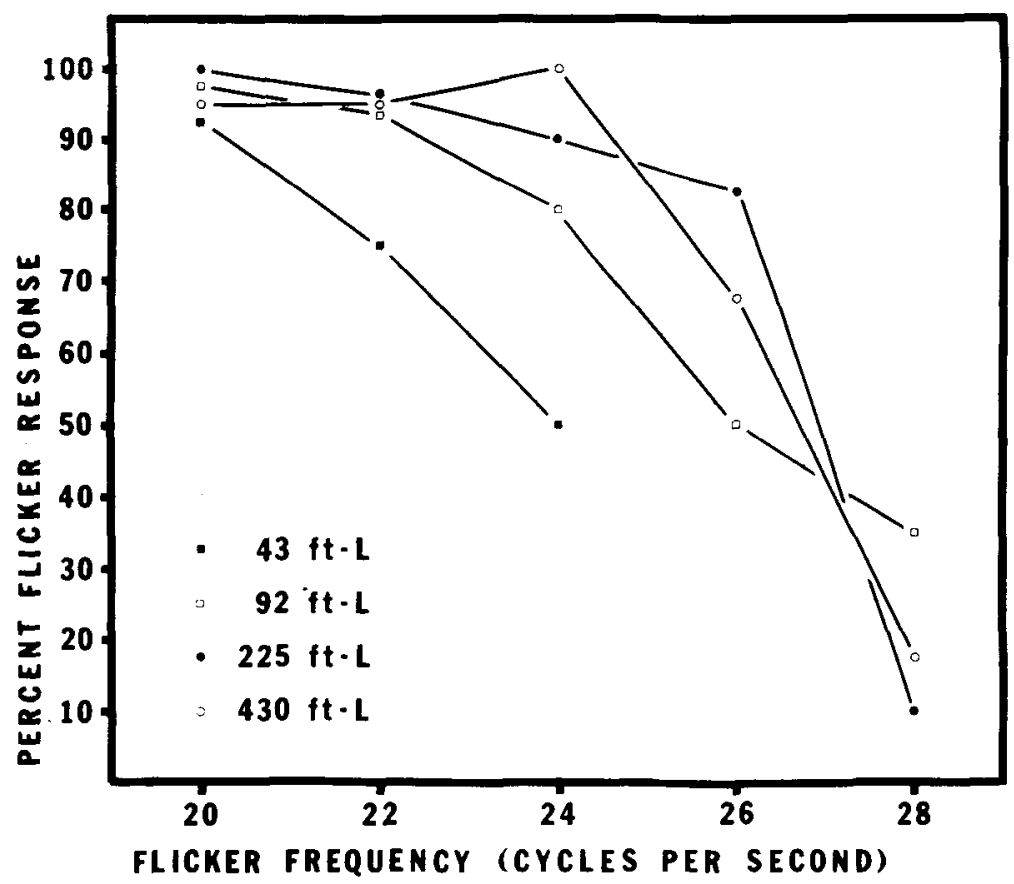

Fig. 2. The mean percent flicker response for two bushbabies, $\mathbf{A}$ and $\mathbf{C}$, as $\mathbf{a}$ function of stimulus frequency and stimulus intensity.

REFERENCES

DARTNALL, H. J. A., ARDEN, G. B. HISAKO, I., LUCK, C. P., ROSENBERG. M. E., PEDLER, C. M. H., \& TANSLEY, $K$. Anatomical, electrophysiological and pigmentary aspects of vision in the bush baby: An interpretative study. Journal of Vision Research, 1965, 5, 399-424.

DETWILER, S. R. Comparative studies upon the eyes of nocturnal lemuroids, monkeys and man. Anatomical Record, 1939, 74, $129-145$.

DODT, E., \& WIRTH, A. Differentiation between rods and cones by flicker electroretinography in pigeon and guinea pig. Acta Physiologica Scandinavica. 1953, 30, 80-89.

HARVEY, L O JR Critical flicker frequency as a function of viewing distance, stimulus size and luminance. Vision Research, 1970, 10, 55-63.

HECHT, S., SHLAER, S. SMITH, E, L HAIG, C.. \& PESKIN, J. C. The visual functions of the complete colorblind. Journal of General Physiology, 1948,31, 459-472.

HECHT, S. \& VERRIJP, C. D. Intermittent stimulation by light. III. The relation between intensity and critical fusion frequency for different retinal locations. Journal of General Physiology, 1933, 17, 251-268.

HECHT, S., \& VERRIJP, C. D. Intermittent stimulation by light. IV. A theoretical interpretation of the quantitative data of flicker. Journal of General Physiology, $1933,17,269-282$

KOLMER, W. Zur Kenntnis des Auges der Primaten. Zeitschrift für Anatomisches Entwickelungsgeschungen, 1930,93 , 679-722.

MISHKIN, M., \& WEISKR ANTZ, L. Effects of cortical lesions in monkeys on critical flicker frequency. Journal of Comparative \& Physiological Psychology, 1959, 52, 660-665.

ORDY, J. M., \& SAMORAJSKI, T. Visual acuity and ERG-CFF in relation to the morphologic organization of the retina among diurnal and nocturnal primates. Vision Research, 1968, 8, 1205-1225.

SILVER, P. H. Spectral sensitivity of a trained bush baby. Vision Research. $1966,6,153-162$.

SVAETICHIN, G. Receptor mechanisms for flicker and fusion. Acta Physiologica Scandinavica, 1956, 39, Supplement, 134, 47-54.

WARD, J. P. DOERFLEIN, R. S., \& RILEY. R. S. The effect of flicker on avoidance acquisition in the bush baby, Galago senegalensis. Psychonomic Science, 1970, 18, 265-266.

WARD, J. P. YEHLE, A. L., \& DOERFLEIN, R. S. Cross-modal transfer of a specific discrimination in the bush baby (Galago senegalensis). Journal of Comparative \& Physiological Psychology, 1970. 73, 74-77. 